\title{
Retrospective Audit of the effect of Anemia on Length of stay [LOS], Transfusion and Acute Kidney Injury[AKI] following Elective Total Knee Replacement [TKR]
}

Dr Ramesh Ananth Manohar1, Dr John Mensah2, Dr Parimala Parthasarathy3. 1 Scunthorpe Hospital, 2 Scarborough Hospital, 3 Scunthorpe Hospital UK.

\section{Background}

$20 \%$ of patients are Anemic before elective Limb Arthroplasty. Preoperative Anemia is associated with increased morbidity, mortality, length of stay, slow functional recovery, blood transfusion and poor quality of life. [1]

\section{Goal of our Audit}

Our goal was to identify the incidence of Anemia in elective TKR patients and their effect on LOS, blood transfusion and AKI at Scarborough Hospital.

\section{Material and Methods}

This was a retrospective audit. 129 consecutive patients who had TKR at Scarborough Hospital were included in the Audit. We recorded the Age, Pre-operative $\mathrm{Hb}$, need for intraoperative or post operative transfusion and creatinine levels. We concluded that any increase in creatinine levels greater than 26 micromole/liter as AKI. We analyzed the data using Word Excel.

\section{References}

1. L.T Goodnough et al. Detection, evaluation and management of Preoperative Anemia in the elective Orthopaedic surgical patient. NATA Guideline. BJA 2011 Jan ; 106 (1) ; 13-22.

\begin{tabular}{|c|c|c|c|c|}
\hline Parameter & Variable & Number & Percentage\% & $\begin{array}{l}\text { Length of stay } \\
\text { in hours [ LOS] }\end{array}$ \\
\hline \multirow[t]{2}{*}{ Age } & $<70$ & 61 & 47 & 62 \\
\hline & $>70$ & 69 & 53 & 95 \\
\hline \multirow[t]{2}{*}{ Haemoglobin[g/dl ] } & $<12$ & 10 & 7.75 & 93 \\
\hline & $>12$ & 119 & 92.25 & 72 \\
\hline \multirow[t]{2}{*}{ Blood transfusion } & Yes & 5 & 3.8 & 125 \\
\hline & No & 124 & 96.2 & 73 \\
\hline AKI with transfusion & Yes & $2 / 5$ & 40 & 125 \\
\hline AKI without transfusion & Yes & $15 / 124$ & 12 & 93 \\
\hline
\end{tabular}

$\underline{\text { Results }}$

$53 \%$ of patients were aged $>70$ years. They stayed 23 hours longer than patients $<70$ years. Our Incidence of Preoperative Anemia was $7.75 \%$. They stayed 21 hours longer than patients with $\mathrm{Hb}>12 \mathrm{~g} / \mathrm{dl} .3 .8 \%$ of patients received blood transfusion during or in the post operative period. Patients who had transfusion stayed 52 hours more than patients who did not have transfusion. AKI was $40 \%$ among patients who had transfusion while $12 \%$ of patients had AKI without transfusion. Patients with AKI in general and particularly patients who had AKI with transfusion stayed longer in the hospital.

\section{Conclusion}

Preoperative anemia, elderly, blood transfusion and AKI prolong the LOS following elective TKR. 